\title{
Ações afirmativas e formação de professores: diálogos e perspectivas a partir do NEAB/UFSCar
}

\author{
Affirmative actions and teacher training: dialogues and perspectives \\ from NEAB/UFScar
}

\section{Acciones afirmativas y formación de profesores: dialogos y perspectivas a partir del NEAB/UFSCar}

\author{
Tatiane Cosentino Rodrigues' \\ Universidade Federal de São Carlos, Professora Adjunta do Departamento de Teorias e \\ Práticas Pedagógicas do Programa de Pós-Graduação em Educação; Coordenadora do \\ Núcleo de Estudos Afro-brasileiros \\ https://orcid.org/0000-0002-4402-2805 \\ Iuanilda Amado Cardoso² \\ Universidade Federal de São Carlos, Doutoranda no Programa de Pós-graduação em \\ Educação; \\ Bolsista do Programa Abdias Nascimento Georgia State University (GSU/UFSCar/CAPES) \\ https://orcid.org/0000-0003-0575-8323 \\ Andreia Rosalina Silua ${ }^{3}$ \\ Universidade Federal de São Carlos, Doutoranda no Programa de Pós-graduação em \\ Educação; Bolsista CNPq \\ https://orcid.org/0000-0003-1708-8961
}

Resumo: Entre os desafios provocados pelo processo de implementação das políticas de ação afirmativa, na modalidade de cotas e/ou reserva de vagas para o acesso ao ensino superior, persiste uma dimensão pouco explorada, que corresponde à produção de ciências e conhecimentos plurais que sejam capazes de alterar padrões desiguais e discriminatórios ainda presentes na sociedade brasileira. 0 objetivo deste artigo é apresentar uma reflexão crítico-propositiva sobre práticas político-pedagógicas a partir da experiência do Núcleo de Estudos Afro-brasileiros da Universidade Federal de São Carlos que têm auxiliado o campo da educação na compreensão de alguns dos desafios provocados pelas políticas de ações afirmativas, especialmente a formação inicial e continuada de professores.

Palavras-chave: Ações afirmativas. Formação de professores. Ensino Superior. Núcleo de Estudos Afro-Brasileiros.

Mestra em Ciências Sociais pela Universidade Federal de São Carlos; Doutora em Educação pela Universidade Federal de São Carlos.

2 Mestra em Educação da Universidade Federal de São Carlos; Doutoranda em Educação no Programa de Pós-graduação em Educação da Universidade Federal de São Carlos.

3 Mestra em Educação pela Universidade Federal de Minas Gerais; Doutoranda em Educação no Programa de Pós-graduação em Educação da Universidade Federal de São Carlos. 
Abstract: Among the challenges posed by the process of implementing affirmative action policies in the modality of quotas and/or reservation of vacancies in access to higher education, there is still an unexplored dimension that corresponds to the production of plural sciences and knowledge that are capable of altering unequal and discriminatory patterns still present in Brazilian society. The purpose of this article is to present a critical-purpose reflection about political-pedagogical practices based on the experience of the Afro-Brazilian Studies Center of the Federal University of São Carlos, which has helped the field of education in understanding some of these policy challenges caused by affirmative action especially the initial and continuing teacher training.

Keywords: Affirmative actions. Teacher training. Higher Education. Center for Afro-Brazilian Studies.

Resumen: Entre los desafios provocados por el proceso de implementación de las políticas de acción afirmativa, en la modalidad de cuotas y/o reserva de vacantes en el acceso a la enseñanza superior, persiste una dimensión poco explotada, que corresponde a la producción de ciencias y conocimientos plurales que sean capaces de alterar patrones desiguales y discriminatorios aún presentes en la sociedad brasileña. El objetivo de este artículo es presentar una reflexión crítica-propositiva sobre prácticas político-pedagógicas a partir de la experiencia del Núcleo de Estudios Afro-brasileños de la Universidad Federal de São Carlos, que han auxiliado el campo de la educación en la comprensión de algunos de estos desafios provocados por las políticas de acciones afirmativas especialmente la formación inicial y continuada de profesores.

Palabras clave: Acciones afirmativas. Formación de profesores. Enseñanza Superior. Núcleo de Estudios Afro-Brasileños.

Recebido em 29 de junho de 2018
Aceito em 29 de maio de 2019
Publicado em 05 de julho de 2019

\section{INTRODUÇÃO}

As políticas de ação afirmativa colocam as Instituições de Ensino Superior diante do desafio de produzir ciências e pluralizar conhecimentos que sejam capazes de alterar padrões desiguais e discriminatórios. Diante dessa demanda, compreendemos a formação de professores como um campo estratégico para romper a herança colonizadora que estrutura a sociedade brasileira, sendo a escola um dos lócus de produção e reprodução desse sistema.

Assim, um dos desafios do campo da formação de professores é o de incluir os debates e os desdobramentos das políticas de ações afirmativas como condição sine qua non 
para a formação dos quadros profissionais no Brasil, já que a presença das diferenças nos bancos universitários pode desafiar, questionar e modificar o currículo eurocêntrico, racista, monocultural e heteronormativo, deslocando discursos para dar destaque às vivências e às experiências dos atores sociais.

A universidade de hoje, que se constituiu durante o século XX, dedicada à formação de uma elite intelectual, oriunda de grupos historicamente privilegiados, capaz de influenciar os destinos da sociedade ou privilegiar apenas um determinado grupo, já não se sustenta mais na contemporaneidade; precisa atualizar-se a partir da demanda e do direito à diferença.

Intelectuais contemporâneos, como Chauí (2001) e Santos (2004), vêm chamando a atenção para que o século XXI seja considerado o século da pluriversidade e não da universidade, em que as instituições de ensino superior devem respeitar e acolher a diversidade de experiências e expressões da população, em que não exista um conhecimento único valorativo, que hierarquiza e converta todos a ele.

Portanto, estudar e discutir de que maneira as universidades e o ensino superior, enquanto espaço intelectual, científico, educativo e político, têm superado o padrão desigual e discriminatório das relações étnico-raciais no seu ambiente cotidiano é fundamental. Bem como verificar como têm sido capazes de influenciar os currículos de formação de professores, as referências teóricas de matrizes étnico-raciais diversas, os procedimentos de pesquisa, as relações pedagógicas e o convívio entre os estudantes e entre estes e seus professores.

Assim, temos como objetivo apresentar, de forma crítico-propositiva, algumas práticas político-pedagógicas desenvolvidas pelo Núcleo de Estudos Afro-Brasileiros (NEAB) da Universidade Federal de São Carlos (UFSCar) que tem auxiliado o campo da educação na compreensão dos desafios pospostos pelas políticas de ação afirmativa e a formação de professores, situando esse Núcleo e/ou grupos correlatos como espaços potenciais de promoção de diálogos no interior das universidades na perspectiva da educação e diferença, bem como têm possibilitado rompimentos com padrões desiguais e discriminatórios. Para tanto, alguns pontos estruturam este artigo, como: uma breve trajetória do NEAB, as percepções ${ }^{4}$ de estudantes do Curso de Pedagogia sobre processos de formação, o levantamento de pesquisas acadêmicas, a atuação de coletivos nas universidades e a importância dos intercâmbios acadêmicos como indicadores da potencialidade das políticas de ação afirmativa.

4 Na esteira dessas discussões apresentamos neste artigo reflexões da dissertação intitulada Educação das Relações Étnicoraciais: limites e possibilidades no Curso de Pedagogia da UFSCar de autoria de Ivanilda Amado Cardoso (2016), orientada pela Prof. ${ }^{a}$ Dra. Tatiane Cosentino Rodrigues, financiado pela CAPES, cujo objetivo consistiu em analisar a política de formação de professores/as para a educação das relações étnico-raciais no Curso de Pedagogia da Universidade Federal de São Carlos (UFSCar). Foram realizadas 16 entrevistas, sendo cinco com professores, e 11 com alunos; alguns trechos das entrevistas foram priorizados como matérias para aprendermos as discussões deste artigo. 
Os debates sobre relações raciais na UFSCar têm registros desde a década de 1970, a partir das iniciativas de estudantes da própria Universidade, da Universidade de São Paulo (USP) e de militantes negros integrantes do Grupo Cultural Congada de São Carlos (GONÇALVES e SILVA, 2012). Esse grupo desenvolvia, com as crianças da cidade, trabalhos de combate ao racismo e à discriminação racial e, a partir das constatações do impacto do racismo no desempenho escolar das crianças, elaborou um projeto "visando à criação de um Grupo de Estudos Afro-brasileiros dentro da universidade [UFSCar] que ficaria responsável por assuntos referentes à problemática do negro." (SLVA, 1987, p. 134).

Segundo Silva (1987), o projeto de criação do grupo de estudo pleiteava um espaço político, porém a Instituição "entendeu que queríamos apenas uma sala para realizarmos nossas reuniões quando, na verdade, o nosso objetivo era de que a universidade assumisse através da pesquisa e infraestrutura, de forma mais eficaz, a questão da discriminação racial." (SILVA, 1987, p. 134).

As reivindicações do Movimento Negro dentro da Universidade e a presença de docentes negros pavimentaram caminhos para o surgimento dos NEABs na década de 1990 . 0 catálogo da Associação Brasileira de Pesquisadores negros - ABPN (2018), até 2014, localizou nas regiões Sudeste (31), Centro-Oeste (11), Norte (12), Nordeste (24) e Sul (21) núcleos e grupos de pesquisa sobre relações raciais vinculados às universidades brasileiras.

Muitos NEABs surgem após o ingresso de ativistas que reivindicavam o espaço da universidade como direito dos negros. Eduardo Oliveira e Oliveira foi um dos ativistas defensores que ainda na década de 1970 reivindicou:

\footnotetext{
Nós temos direito a essa instituição, sobretudo essa aqui [a USP] que é pública. E o fato de fazer la Quinzena do Negrol dentro da universidade é para que a universidade assuma sua responsabilidade para formar mais negros, para que possam, como Beatriz [Nascimento], que passou por uma universidade, de ir ao quilombo, à favela, seja lá onde for, e dar os ensinamentos dela lá. Agora, sem uma universidade, sem um crédito, seria até impossivel eu conseguir esta semana aqui, porque eu seria apenas um negro. Hoje, depois de dez anos ou doze anos de trabalho, já me mandam entrar e sentar, porque eu sou Eduardo de Oliveira e Oliveira, que tem um título, que não pretende ser doutor, que não se branqueou, mas que usa disso como instrumento de trabalho para poder se afirmar como negro e ajudar a que outros negros se afirmem como tal. (TRAPP, 2017).
}

Eduardo de Oliveira e Oliveira foi o primeiro autoidentificado negro a entrar na graduação e na pós-graduação em Ciências Sociais da Universidade de São Paulo, em 1968 (TRAPP, 2017). Em sua curta atuação como docente na UFSCar, que perdurou de 1979 a 1980 quando faleceu, o sociólogo teve um papel importante para a criação do NEAB-UFSCar nos 
anos 1990. Oliveira e Oliveira foi talvez o principal articulador do diálogo entre o Movimento Negro e a Universidade, conforme afirma a professora Petronilha B. Gonçalves e Silva (2012), "a proposta de reconhecimento da contribuição negra na sociedade brasileira, entra academicamente aqui na universidade com o professor Eduardo Oliveira e Oliveira [...]" Eduardo de Oliveira e Oliveira nasceu no Rio de Janeiro em 1924, "[...] dedicou grande parte da sua vida à luta em benefício da comunidade negra, sendo um dos pioneiros a apontar propostas para a construção da Lei Caó - Lei n 7.437, de 20 de dezembro de 1985." ${ }^{5}$ (SANTIAGO, 2010, p. 13).

No Acervo da Unidade Especial de Informação e Memória (UEMM) encontra-se a Coleção Eduardo de Oliveira e Oliveira, que foi utilizada como fonte para a produção de um Inventário Analítico arquivando mais de 2.200 documentos pessoais e a bibliografia intelectual do pesquisador. Nos acervos do NEAB-UFSCar, arquivados na UEM, também constam registros da história de outros militantes e professores negros de outras universidades. São as Coleções: Ivair Augusto dos Santos, Thereza Santos, Irmã Raimunda, Coleção Rachel de Oliveira e Coleção Projeto "Salve o 13 de Maio 1986-1988?"; há também um Inventário Analítico da Escravidão em São Carlos. ${ }^{7}$ Esses acervos constituem-se em fontes profícuas para o desenvolvimento de pesquisas acadêmicas. ${ }^{8}$

Em sua trajetória de atuação, o Núcleo tem desenvolvido inúmeros Programas e Projetos destinados à formação de professores das escolas da rede de Educação Básica do Estado de São Paulo. Informações detalhadas sobre os projetos podem ser consultadas no Histórico do NEAB disponível no seu site. ${ }^{9}$

0 NEAB-UFSCar, em conjunto com outras instituições, entidades e professores foi um espaço político significativo no processo de elaboração do texto do Parecer CNE/CP 003/2004 e da Resolução CNE/CP 001/2004 que regulamenta a Lei n. 10. 639/03, em virtude da presença da professora Petronilha Gonçalves e Silva no Conselho Nacional da Educação por indicação do Movimento Negro.

5 Lei n. 7.437, de 20 de dezembro de 1985, que inclui entre as contravenções penais a prática de atos resultantes de preconceito de raça, de cor, de sexo ou de estado civil - nos termos que conhecemos atualmente (BRASIL, 1985).

6 Lotado no Centro Acadêmico Educação e Ciências Humanas (CECH).

7 Mais informações sobre os acervos em: http://www.ueim.primeiraguerra.com.br/ (UEIM) e http://www.neab.ufscar.br/ biblioteca-digital (Biblioteca NEAB-UFSCar).

8 No âmbito do NEAB foram desenvolvidas pesquisas utilizando como fonte os acervos que constam na UEIM. A título de exemplo, podemos localizar o trabalho de Santiago (2010) e de Oliveira (2008). A monografia Potencialidades Pedagógicas para a Educação das Relações Étnico-raciais em imagens integrantes da Coleção Professor Eduardo de Oliveira e Oliveira, de Flávio Santiago (2010), e a dissertação de Mestrado Narrativas de Thereza Santos - contribuições para a educação das relações étnico-raciais, de Evaldo Ribeiro Oliveira (2008). Ambas as pesquisas foram orientadas pela Prof. ${ }^{\circ}$ Dra. Petronilha Beatriz Gonçalves e Silva. 0 Projeto 13 de Maio? Foi um Projeto desenvolvido pela Secretaria de Estado da Educação de São Paulo no período de 1986-1988. 0s depoimentos e materiais do projeto na cidade de Ribeirão Preto foram registrados por Ana Paula Santos, Ana Maria Ciarlo e Marco Antônio Ciarlo em CD-ROM A criança negra e a escola: inventário da Coleção Projeto "Salve 13 de maio"? Exemplares do CD-ROM encontram-se no acervo do NEAB/UFSCar.

90 histórico do NEAB está disponivel em http://www.neab.ufscar.br/?.page_id=5500. 
Após a aprovação das Diretrizes Curriculares Nacionais para a implementação da Educação das Relações Étnico-Raciais (DCNs ERER), a professora Petronilha organizou em 12 agosto de 2004 uma Reunião de Trabalhos, Parecer CNE/CP003/2004: Estratégias para Implantação e Avaliação. Essa primeira reunião contou com a participação de 63 pessoas, sendo representantes da comunidade de diferentes níveis de ensino e militantes do Movimento Negro. No dia seguinte, ocorreu uma segunda reunião com o Grupo de Trabalho ${ }^{10}$ para Acompanhamento e Avaliação da Implantação do Parecer CNE/CP 003/2004 e da Resolução CNE/CP 001/2004" (BRASIL, 2004a, 2004b).

A realização dessa reunião de trabalho pode ser considerada um avanço na construção de uma agenda nacional para a ERER, tendo em vista que a construção do documento se adotaram diferentes estratégias de diálogos com a comunidade acadêmica e não acadêmica representante das diferentes regiões do País.

Outra contribuição importante para o campo da formação de professores realizada pelo NEAB em articulação com o Departamento de Sociologia da UFSCar, em virtude da presença do Prof. Dr. Valter Roberto Silvério na Organização das Nações Unidas para a Educação (Unesco), foi a organização e tradução para a língua portuguesa dos oito volumes da História Geral da África, além dos dois livros Sínteses da Coleção, em parceria com a Unesco e a Secretaria de Educação Continuada, Alfabetização, Diversidade e Inclusão do Ministério da Educação (SECADI).12

Com a finalidade de auxiliar o uso pedagógico desse material, sob a coordenação da Prof. ${ }^{\circ}$ Dra. Nilma Lino Gomes, foram elaborados os livros História e Cultura africana e Afrobrasileira na educação Infantil e Brasil/África: Histórias Cruzadas Ensino Fundamental I e || para professores. Para implementação das metodologias indicadas nos livros, o NEAB iniciou em 2014, sob a coordenação da professora Tatiane Cosentino Rodrigues e professor Valter

10 Nesse grupo de trabalho, participaram importantes pesquisadores da área da educação e das relações raciais. Consultora: Prof. ${ }^{a}$ Dra. Joyce Eliane King; Comissão Coordenadora: Prof. ${ }^{a}$ M.e Bartolina Ramalho Catanante (TEZ); Prof. Dr. Henrique Cunha Júnior (UFC); Prof. ${ }^{a}$ Dra. Nilma Lino Gomes (UFMG); Prof. Dr. Paulino de Jesus Francisco Cardoso (UESC); Prof. ${ }^{a}$ Dra. Petronilha Beatriz Gonçalves e Silva; Prof. ${ }^{a}$ Técnica em Educação Véra Neusa Lopes; Prof. Dr. Vilson Caetano de Sousa Júnior (UNEB/ FIB). Colaboradores: Andréia Lisboa de Souza (SECA/MEC); Anete Abramowicz (UFSCar); Dener S. Silveira (UFSCar); Duílio Duka de Souza (APEOESP/CNTE); Edna Roland (Unesco); Emília Freitas de Lima (UFSCar/ANPED); Francisca Novantino Paresi (CNE)lolanda de Oliveira (PENESB/UFF); João B. Nazareth Jr. (SIMPEEM); José Roberto Camargo de Souza (CNCD); Lúcia Helena Lodi (MEC/ Secretaria de Educação Básica); Márcia Terra Reis (ONG Diálogo Pesquisa e Assessoria em Educação Popular - Secretaria Municipal de Direitos Humanos e Segurança Urbana - Porto Alegre); Maria Clara Di Pierro (Ação Educativa/Concurso Negro e Educação); Maria José Cordeiro de Jesus (POSGRAD); Maria Waldenez de Oliveira (UFSCar); Marisa A. D. Demarzo (UFSCar); Miguel Arroyo (UFMG); Rachel de Oliveira (Rede Pública do Município de São Paulo/NEAB/UFSCar); Regina Conceição (Secretaria Municipal de Educação de São Carlos); Reginaldo de Souza Silva (UESB/UC - Museu Pedagógico); Rita de Cássia Marino (Secretaria Municipal de Educação de São Carlos); Sandra Silveira (Fundação Cultural Palmares); Suelaine Carneiro (Ação Educativa/Concurso Negro e Educação); Vanessa Mantovani Bedani (NEAB/UFSCar).

" Regulamenta a alteração trazida à Lei n. 9394/96 de Diretrizes e Bases da Educação Nacional e institui Diretrizes Curriculares Nacionais para a Educação das Relações étnico/raciais e para o Ensino da História e Cultura Afro-Brasileira e Africana.

12. Em 2011 a SECAD incorporou os programas de Educação Inclusiva do MEC e passou a denominar-se SECADI. 
Roberto Silvério, ${ }^{13}$ o Curso de Aperfeiçoamento em Educação das Relações étnico-raciais para formação de três mil professores, gestores, coordenadores e demais profissionais da rede de ensino da Cidade de São Carlos e região. ${ }^{4}$

Ao longo da história dos NEABs brasileiros têm analisado as relações interpessoais, culturais, sociais e econômicas, mantidas pelos afrodescendentes brasileiros, e os resultados de pesquisas acadêmicas, bem como as atuações politicas dos Núcleos foram fundamentais no processo de aprovação da constitucionalidade e implementação das ações afirmativas e reserva de vagas para estudantes negros, pobres e indigenas nas universidades públicas.

A UFSCar é uma instituição reconhecida por ser um marco, no Estado de São Paulo, para a institucionalização das políticas de ações afirmativas de reservas de vagas para negros e alunos de escolas públicas e para a aplicação de vestibular específico para indigenas ${ }^{15}$ e refugiados, com regras específicas. Somam-se ao reconhecimento os programas de convênio para alunos oriundos de paises latino-americanos e africanos (Programa Estudante - Convênio de Graduação PEC-G), o curso de graduação em Pedagogia da Terra e de Agronomia, o Programa Institucional de Bolsas de Iniciação Científica nas Ações Afirmativas (PIBIC/Af/CNPq) e o cursinho pré-vestibular popular foram institucionalizados nessa Universidade.

A UFSCar não foi a primeira instituição a propor ações afirmativas, outras universidades brasileiras já haviam implementado políticas de ações afirmativas desde 2002, como é o caso da Universidade do Estado da Bahia (UNEB), Universidade Federal da Bahia (UFBA), Universidade Estadual do Rio de Janeiro (UERJ) e Universidade de Brasilia (UNB), esta última desde 2003.

0 primeiro vestibular por ações afirmativas para alunos de escolas públicas e autodeclarados pretos, pardos e indigenas ocorreu em 2007; os primeiros estudantes

13 Segundo informações da Professora Petronilha, durante sua trajetória, o NEAB organizou-se em formato de colegiado e os professores pesquisadores vinculados representam e respondem institucionalmente pelo Núcleo. Nesse formato de coordenação colegiada foram representantes os/as seguintes docentes: Prof. Dr. Álvaro Rizzoli; Prof. ${ }^{\circ}$ Dra. Petronilha Beatriz Gonçalves e Silva; Prof. ${ }^{\circ}$ Dra. Lúcia Maria de Assunção Barbosa (1995-2010) e Prof. Dr. Valter Roberto Silvério. Desde 2013, é coordenado pela Profa. Dra. Tatiane Cosentino Rodrigues e pelo Prof. Dr. Douglas Corrêa da Silva.

140 curso atende ao Termo de Ajustamento de Conduta (TAC n. 1.34.000189/2006-32) junto ao Ministério Público Federal/ Procuradoria da República do Município de São Carlos e visa atender as determinações da Lei de Diretrizes e Bases da Educação Nacional (n. 9.394/1996), alterada pela Lei n. 10.639/2003 e posteriormente pela Lei n. 11.645/2008, e do Parecer n. 03/2004, que trata das Diretrizes Curriculares Nacionais para Educação das Relações Étnico-Raciais e para o Ensino de História e Cultura Afro-Brasileira e Africana. A formação ocorreu na Universidade e nos municípios de Descalvado, lbaté, Pirassununga, Porto Ferreira, Ribeirão Bonito, Santa Cruz da Conceição, Santa Cruz das Palmeiras, Santa Rita do Passa Quatro, São Carlos e Tambaú.

15 A Universidade Estadual de Londrina, que já havia implementado o vestibular indigena, prestou assessoria à UFSCar no processo de implementação da política em 2008. 
cotistas ingressaram em 2008. ${ }^{16}$ Segundo a Coordenadoria de Ingresso na Graduação, com base no primeiro modelo de ações afirmativas da UFSCar, entre 2010 e 2012, de um total de 270 candidatos ingressantes no Curso de Pedagogia (diurno e noturno), $7 \%$ é a porcentagem correspondente ao ingresso de alunos que se autodeclaram pretos e pardos, e que cursaram integralmente o ensino médio em estabelecimentos da rede pública, sendo $26 \%$ os ingressantes pelo critério de escola pública isoladamente.

A partir de 2013, quando as ações afirmativas passam a vigorar, com base na Lei n. 12.711, de 29 de agosto de 2012, e a partir desta observa-se uma ampliação da porcentagem da autodeclaração de pertencimento racial em geral. Dados da Coordenadoria demonstram que entre 2013 e 2015 do total de 269 candidatos ingressantes no Curso de Pedagogia, 13\% se autodeclararam pretos, pardos ou indígenas, e $20 \%$ correspondiam a candidatos que cursaram integralmente ensino médio na escola pública.

Para os alunos entrevistados, na pesquisa de mestrado desenvolvida por Cardoso (2016), as políticas de ações afirmativas impactaram positivamente na composição étnico-racial da Universidade: "Uma das coisas que mais me impactou foi a cara da universidade que tinha mudado, ver negros na universidade era coisa que eu não via na minha época de graduação." (Entrevista 002 A) (CARDOSO, 2016).

A trajetória de vida e as reflexões críticas sobre o que é ser jovem negro na sociedade brasileira aparecem, nas entrevistas, de forma articulada com a vida acadêmica do aluno $013 \mathrm{~A}$. Esse é um exemplo salutar de que a formação docente não ocorre apenas nos bancos universitários e que os alunos apresentam ricas vivências que a universidade poderia potencializar e valorizar para ampliar as discussões sobre diferentes temáticas e, sobretudo, sobre relações raciais nos processos formativos.

E: foi tanto esse quanto [...] alguns documentários que surgiram assim do
nada. Tem um que é, que chama Preto contra branco, que conta sobre
um jogo de futebol que acontece em Heliópolis que é muito bacana. Tem
um outro que é, como é o nome? [pausa] Ai, meu Deus, é o Preto contra
branco... o Zumbi somos nós, que é fantástico, é absurdo assim, que conta
história de um médico negro que estava correndo num determinado bairro
nobre aí e confundiram ele com um ladrão e o assassinaram; tem a Frente
3 de Fevereiro que fez isso, e tem uma série de outras coisas. A música
que você ouve, tem, por exemplo, um grupo de Rap que eu ouço muito que
é os Z'África Brasil que trata muito disso. E aí você fala "Poxa cara tem

16 Em novembro de 2015, em um evento promovido pela Secretaria Geral de Ações Afirmativas, Diversidade e Equidade, foi lançado o livro Ações Afirmativas: Perspectivas de pesquisas de estudantes da reserva de vagas, organizado pela professora Petronilha Beatriz Gonçalves e Silva e pelo doutorando Danilo de Souza Morais. 0 livro apresenta a trajetória das Ações Afirmativas na UFSCar e divulga as pesquisas de iniciação científica desenvolvidas pela primeira turma de estudantes ingressantes pelas reservas de vagas. 
muita coisa ail" A gente tem que correr atrás disso tudo. (Entrevista $013 \mathrm{~A}$ ) (CARDOSO, 2016, grifo nosso).

Ao longo de toda a entrevista, o aluno $013 \mathrm{~A}$ mencionou ricas informações que servem de sugestões para os currículos de cursos de formação de professores. Por exemplo, nos trechos anteriormente expostos o aluno cita o movimento social Frente 3 de Fevereiro, que pode ser tomado como subsídio para discutir o Mapa da Violência e o extermínio da juventude negra; os documentários Zumbi somos nós e Preto contra branco citados também abririam profícuas discussões sobre relações raciais no Brasil. ${ }^{17}$ Valorizar os lugares de fala dos diferentes grupos sociais envolvidos no processo de aprendizagem é uma prática necessária à Educação. Em entrevista, o aluno $013 \mathrm{~A}$ afirma que sua turma é democrática e ouve suas experiências e análises.

E: ah! As pessoas ouvem, ouvem, é supertranquilo e democrático. Eu acredito, não sei o que dentro de cada um se passa, "Ah, esse cara está falando besteira". Mas eu acho que essa coisa, a gente tem sessenta e sete por cento das pessoas que morrem por homicídio são negras. A gente tem uma polícia que arrebenta, então, se a gente for parar para pensar os últimos casos aí, acho que a Cláudia que foi ano passado, Amarildo, o menino Eduardo, tudo ai, entendeu? A gente sabe quem está morrendo, por exemplo, entendeu? E ai tem que colocar, é difíil... As pessoas vão debater, vão, mas é uma coisa que está escancarada [...] (Entrevista 013 A) (CARDOSO, 2016).

Apesar de o aluno entrevistado afirmar existir uma sensibilidade por parte da sala para entender suas vivências, uma aluna indígena afirma que a turma apresenta expectativas preconceituosas quanto ao seu desempenho nas atividades acadêmicas.

[...] foi dificil porque era uma coisa nova para eles, mas uma coisa que eu observo é quando eu vou apresentar os seminários, eles ficam meio, nossa! Como que ela vai falar, como que ela [...] eu ainda sinto que eles

17 Como autodefine-se, a Frente 3 de Fevereiro é um grupo transdisciplinar de pesquisa e ação direta acerca do racismo na sociedade brasileira: "o nome do grupo faz alusão à data da morte do médico negro Flávio Ferreira Sant'Ana assassinado pela polícia no Estado de São Paulo, em 3 de fevereiro de 2004, após ser confundido com um assaltante que segundo as descrições do denunciante, era um "homem negro". Ser negro foi o único elemento utilizado pela polícia para executar Flávio. Em 2007, a Frente 3 de Fevereiro produziu um vídeo documentário Zumbi somos nós para despertar reflexões sobre o racismo e a morte dos jovens negros. Sobre a Frente 3 de Fevereiro, ver: http://www.frente3defevereiro.com.br/. Outro documentário citado pelo entrevistado, Preto contra Branco foi produzido pelo diretor Wagner Morales e discute o preconceito racial no Brasil, usando como referência um "clássico" do futebol de várzea entre moradores de dois bairros periféricos de São Paulo. 0 grupo Z'africa Brasil, que também é citado pelo aluno 013 A destaca-se como um dos principais grupos de hip-hop na cena musical do País. Ao longo de sua trajetória de 20 anos, o grupo com sua arte influencia e inspira gerações (Z'AFRICA, 2018). No livro 0 Atlântico Negro, Paul Gilroy propõe uma reorientação conceitual sobre as teorias culturais e apresenta a música negra como manifestação da política negra na escravidão. 
me veem como uma pessoa diferente dentro da sala apesar de eu ter amizade com todo mundo, mas ficam "Será que ela vai abordar o tema bem? Será que ela vai ter alguma... será que ela vai alcançar os objetivos? Será que ela vai conseguir explicar como a gente explica? Inclusive na terça-feira eu apresentei um seminário falando de contação de história, e nessa apresentação de seminário eu percebi, assim, tipo a colega veio e falou: "Você está nervosa? Tipo, é indígena, não vai saber se expressar bem, você está nervosa? Aí ela riu, eu simplesmente disso não! Aí quando eu fui falando do tema que eu trabalho com as crianças na UAC dá para perceber que as pessoas te veem diferente, sempre vai te ver diferente e inclusive a minha menina estava falando... a minha filha falou assim: "Até os professores quando vai falar do povo indigena eles te olham bem assim, nossa! $E$ até a gente fica sem jeito." Inclusive ela falou lnossa mãe tem horas que eu fico... não sei, as pessoas começam a me olhar de um jeitol. Aí eu falei: "Você tem que tirar isso da cabeça deles, você tem que debater com o professor, entendeu? A gente sempre vai ser visto diferente, a gente nunca vai ser visto como eles como os não indígenas, a gente é visto assim. (Entrevista 016 A) (CARDOSO, 2016).

0 relato da estudante indígena lança à universidade questões paradigmáticas fundamentais que demonstram a urgência e a importância da ampliação dos debates sobre educação e diferença para que sejam produzidos novos olhares, saberes, metodologias de ensino e currículos. Um paradigma posto à educação para as diferenças, como fronteiras aos processos de implementação das Leis n. 10.639/03 e n. 11.645/08.

0 ingresso de grupos historicamente excluídos na universidade, no que se refere às trocas cotidianas, tem apresentado algumas mudanças de percepção acerca dos grupos subrepresentados, mas ainda são mudanças superficiais. Nesse sentido, o desafio das universidades, dos NEABs e dos grupos de estudos, professores pesquisadores no campo das relações raciais para viabilizar caminhos que possibilitem aos alunos atravessar a linha abissal que invisibiliza suas experiências para se apropriarem de conhecimentos e formas de pensar referenciadas pelo diálogo das diferenças (SANTOS, 2007).

Santos (2007) defende a tese de que o pensamento moderno ocidental é abissal, o qual divide a realidade social em dois universos distintos, isto é, em duas linhas em que o "outro lado" torna-se invisível, inexistente. Na sua tese duas categorias são fundamentais para a análise: regulação/emancipação, que, segundo o autor, é uma dicotomia que se aplica nas sociedades metropolitanas e fundamenta todos os conflitos modernos. Do outro lado da linha, ou seja, nas sociedades coloniais existe a outra categoria apropriação/violência, que funda a primeira.

Para Santos (2007), o pensamento abissal se manifesta no conhecimento e no direito; no primeiro, o pensamento abissal distingue o que é verdadeiro e falso com base na ciência em detrimento dos conhecimentos filosóficos e teológicos. Desse modo instaura formas de verdades científicas e não científicas, "refiro-me aos conhecimentos populares, 
leigos, plebeu, camponeses ou indígenas do outro lado da linha que desaparecem como conhecimentos relevantes." (SANTOS, 2007, p. 72-73).

Para o sociólogo, no campo do direito, o pensamento abissal é caracterizado por aquilo que é considerado legal e ilegal com base no direito oficial do Estado ou internacional. Tal distinção deixa de fora outros territórios sociais e os considera alegais e sem lei. Em suma, o pensamento abissal manifestado na ciência e no direito torna invisíveis as experiências que estão do "outro lado da linha", o que para Santos (2007) é a zona colonial, decorrente da linha global que separou o velho mundo e o novo mundo, constituindo-se como o universo das crenças, dos comportamentos incompreensíveis e da animalização dos povos indígenas.

Mediante essas categorias, Santos (2007) nos possibilita compreender como as construções epistemológicas fundamentadas na ciência e no direito formulam conceitos que legitimam e possibilitam a inversão e a dominação de territórios indígenas, autorizando a aplicação da regulação/emancipação sem que esta entre em contradição com a apropriação/ violência que está no âmbito do colonial, como já foi mencionado e, portanto, envolve cooptação, assimilação, o que no caso da violência implica a destruição física, material cultural e humana.

Santos (2007) destaca o papel central das universidades, escolas e centros de pesquisas na implementação do pensamento abissal e, ainda, destaca que a negação da humanidade forjada na modernidade, ou seja, na concepção de raças subumanas é tão presente na atualidade como no período colonial, por isso o autor cita Guantánamo e outras práticas desumanas, como exemplos de manifestações do pensamento abissal ainda presente na modernidade.

0 acesso ao ensino superior tem criado um perfil de atores sociais diferente do daqueles militantes da década de 1970 e 1980, quando estes apresentavam uma postura autônoma na apropriação teórica sobre relações raciais no Brasil. Assim podemos localizar grupos de estudos independentes que foram pioneiros nas leituras de autores fundamentais para entender o contexto que se apresentava, como Beatriz Nascimento, Lélia Gonzáles, Guerreiro Ramos, Abdias Nascimento, entre outros intelectuais nacionais e estrangeiros que apareceram nas discussões acadêmicas anos mais tarde quando esses militantes começam a acessar a universidade como graduandos, pós-graduandos e professores que constroem um "novo" conhecimento na luta (GOMES, 2017).

Ao mesmo tempo que é possível projetar na nova geração a possibilidade de continuação da atuação política no combate ao racismo, esse mesmo grupo, em processo de formação política, pouco tem acompanhado e se apropriado das ações e estratégias, empreendidas por militantes da década de 1970 aos anos 2000, que possibilitaram alguns avanços na política educacional. Essa é a crítica do docente $001 \mathrm{D}$ : 
[..] então, esse esforço digamos assim, de você colocar para as novas geraç̃̃es que o que aconteceu até o presente momento não é o final da história, é o início de outra história, é muito complexo, porque o desafio que está colocado para nós brasileiros que estamos nessa labuta é exatamente formar as novas gerações com o perfil muito diferente do que nós fomos formados. É o perfil de pesquisador, perfil de pesquisador que circula, de pesquisador que sabe ler em outro idioma, porque se não isso não vai... você não consegue fazer mudanças. (Entrevista 001 D) (CARDOSO, 2016).

0 acesso ao ensino superior desafia a juventude brasileira a assumir 0 compromisso de pesquisadores que circulam e acessam literaturas em outras línguas para conhecer epistemologias e influenciar agendas "[...] para que possam, como Beatriz Nascimento, que passou por uma universidade, de ir ao quilombo, à favela, seja lá onde for [...]" e poderem também ensinar (OLIVEIRA e OLIVEIRA apud TRAPP, 2017). No entanto, outros fatores implicam a efetivação dessa questão; não diferente da realidade de negros e pobres de gerações anteriores, esses sujeitos ingressam na universidade com as responsabilidades de cumprir o currículo estabelecido para sua titulação, desenvolver teorias e aprender estratégias de sobrevivência e permanência na universidade.

Diante desse contexto alguns problemas desafiam as instituições e os próprios estudantes a se questionarem: em que condições materiais, fisicas e psicológicas estudantes negros, indígenas, população GLBTT e pobres produzem conhecimentos? Como a juventude tem construído conhecimento? 0 que está posto à juventude do século $\mathrm{XXI}$ e quais questões sociais mobilizam a sua produção? Qual projeto de sociedade justifica o ingresso de jovens oriundos de grupos historicamente oprimidos na graduação e pós-graduação? Como os resultados das produções acadêmicas podem influenciar agendas para o enfrentamento do racismo?

Quanto à qualidade acadêmica de estudantes egressos de programas de ações afirmativas, muitas pesquisas, como, por exemplo, as análises de Passos (2015), demonstram resultados positivos, revelando desempenhos significativos de sucesso acadêmico. 0 que está posto no contexto atual é o levantamento sistematizado de como as pesquisas produzidas nas últimas décadas podem influenciar agendas e pluralizar conhecimentos para construir novas pedagogias e epistemologias capazes de romper com padrões desiguais e discriminatórios impostos pelo racismo estrutural e explícitos nas políticas governamentais marcadas por retrocessos.

Além dos elementos até aqui mencionados, a produção acadêmica também é um indicador importante para a nossa compreensão do universo em que vem se desenvolvendo - Curso de Pedagogia da UFSCar. Nesse sentido, em pesquisa anterior realizamos um levantamento bibliográfico na base da Biblioteca Comunitária da UFSCar e em arquivos do Curso de Pedagogia desta, para demonstrar esse quadro conjuntural cujas finalidades seriam: projetar a produção acadêmica da UFSCar, localizar os principais agentes orientadores, 
construir um instrumento de pesquisa sobre educação das relações étnico-raciais para subsidiar trabalhos de outros pesquisadores, principalmente estudantes que estão iniciando a elaboração de TCC e outros projetos de pesquisa. 0 resultado do levantemento de teses e dissertações pode ser consultado no artigo Relações étnico-raciais na produção científica do PPGE/UGFSCar, de Cardoso, Santos e Rodrigues (2017).

No período de janeiro de 2003 a fevereiro de 2015 no Programa de Pós-graduação em Educação da UFSCar foram realizadas 607 pesquisas na pós-graduação, sendo 402 de mestrado e 205 de doutorado. Desse total, identificamos no Repositório Institucional da UFSCar que 47 pesquisas abordaram especificamente o tema da educação das relações étnicoraciais, sendo 32 trabalhos de Mestrado e 15 de Doutorado, representando $7 \%$ das pesquisas defendidas sobre essas relações no Programa. Dessas 47 pesquisas produzidas naquele período, 20 trabalhos estão entre dissertações e teses que foram orientadas pela professora Petronilha Beatriz Gonçalves e Silva. Os dados desse levantamento explicitam o papel fundamental da presença de docentes negros e do NEAB na produção de conhecimento na pós-graduação da UFSCar, por outro lado expressa o desafio institucional em transversalizar a temática na universidade brasileira para que os debates das relações raciais sejam analisados em diferentes programas e linhas de pesquisa da pós-graduação.

A pesquisa realizada por Cardoso (2016) também evidenciou a baixa incidência da temática nos trabalhos acadêmicos em nível de graduação. Da análise da produção de seis turmas do Curso de Pedagogia, entre 2003 e 2008, foram encontradas 176 monografias, sendo que cinco delas trataram da temática racial e nenhuma tratou especificamente da formação de professores para a educação das relações étnico-raciais. Observa-se um número crescente de alunos interessados na temática após 2010 quando se torna obrigatório o componente curricular Didáticas das Relações Étnico-raciais. A oferta do componente curricular optativo Sociedade, Educação e Relações Étnico-Raciais, ofertado em 2013-1 e 2014-2, também influenciou a produção discente em nível de TCC. No currículo lattes dos respectivos professores dos componentes curriculares constavam cinco trabalhos com orientação concluída e em andamento. No currículo lattes do Prof. Dr. Manoel Nelito também localizamos quatro trabalhos com orientação concluída ou em andamento. Ou seja, entre 2010 e 2014 totalizaram quase o dobro de pesquisas em relação ao período de 2003 e 2008, o que demonstra a relevância dos componentes para a ampliação da produção científica.

Também a oferta dos componentes curriculares demonstra passos importantes para mudanças estruturais, uma vez que se garante um quadro docente, carga horária expressiva, conteúdos e bibliografias específicas do campo das relações raciais.

Além dos componentes curriculares outros espaços extracurriculares foram importantes para o processo de formação dos alunos, alguns nas entrevistas mencionaram os seguintes espaços; eventos científicos (Semana Acadêmica Africana, IV Seminário 
Internacional de Educação Infantil e Pós-Estruturalismo); Cinema Negro - ministrado pela professora Dra. Janaína Damasceno (ACIEPEs), Sociologia das relações étnico-raciais ofertado no Departamento de Sociologia pelo Prof. Dr. Valter Silvério Diretório Central dos Estudantes (DCE), que integrava estudantes de pedagogia participantes do NEAB, PIBID, Coletivo Café das Pretas, e o NEAB também é mencionado pelos alunos entrevistados como núcleo importante para a formação na perspectiva das relações étnico-raciais.

As percepções dos estudantes do Curso de Pedagogia também são um forte indicador de como o NEAB ao longo da sua atuação foi significativo para a formação de professores e ao longo da sua trajetória tem contribuído para romper com desigualdades. Trechos de entrevistas com alunos da UFSCar são ilustrativos da importância de docentes membros do NEAB no seu processo de formação na Instituição, e mais especificamente de alunos do Curso de Pedagogia.

[..] mas eu não posso avaliar como o curso está hoje. 0 que eu posso falar é do meu curso da minha época. Porque, assim, na verdade, eu acho que a gente se fechava muito em grupos; a gente ia, quem era estudante e frequentava o NEAB tinha esse tipo de discussão, se você não frequentava - NEAB você não tinha esse tipo de discussão, você passa pelas disciplinas. No meu ponto de vista durante minha formação não foi implementada as diretrizes no curso. (Entrevista 09A).

[...] acredito que o NEAB é fundamental para a universidade. 0 NEAB, que a gente sabe que tem uma luta fantástica, a professora Petronilha e o Valter, que são pessoas que sempre lutaram pelas ações afirmativas, então, o NEAB é... ah, sei lá, é uma coisa maravilhosal Não só em termos de UFSCAR, em termos do Brasil, se a gente parar para pensar, porque a gente sabe que o NEAB é o grande [...] (Entrevista $013 \mathrm{~A}$ ).

[... sim, por exemplo, eu acho que a minha formação em relação aos assuntos das relações étnico-raciais não se deu dentro das salas de aula, mas, sim, nos corredores, nos departamentos do projeto de extensão que eu participei, das reuniões do NEAB, nas discussões do $P Q$, nas discussões com outros colegas. Porque se fosse depender da estrutura rígida do curso eu não teria essas discussões que tenho hoje. (Entrevista 009 A).

Já; nessa época já tinha. Já tinha estudantes da Pedagogia que eram do NEAB e que eram do C.A e traziam as discussões para a gente e ajudavam, ajudavam os outros que não tinham essa formação além da [...] dos sistemas, nessa época já tinha, sim. (Entrevista 002 A) (CARDOSO, 2016).

Mas apesar da significativa trajetória do Núcleo, o fato de não fazer parte do organograma da Universidade, coloca o NEAB em paradoxo, pois se a não institucionalização the confere maior autonomia em suas ações acadêmicas, também dificulta a realização de 
alguns projetos, já que não conta com dotação orçamentária. 0 relato de um dos participantes da pesquisa é significativo para problematizar essa questão:

[...] não é um núcleo institucionalizado, a sua permanência na universidade depende dos departamentos. Então, por exemplo, o que caracteriza um núcleo institucionalizado dentro de uma universidade é que todo núcleo institucionalizado [...] ele é uma instância orçamentária, ele recebe um orçamento, ou ele pode gerir recursos que ele receba. 0 NEAB não pode fazer isso. Os outros núcleos da universidade podem e inclusive tem lá uma linha do orçamento da própria instituição ou de recursos extra orçamentária da instituiição para poder realizar suas atividade. Então, todas as atividades que o NEAB realizou até hoje ele realiza porque passa pelo departamento de Sociologia, passa pelo departamento de Metodologia, passa pelo departamento de Práticas Pedagógicas. Então, nesse sentido ele não é institucionalizado, agora e... e quando a universidade discutiu a criação de núcleos de extensão, o NEAB não foi chamado, ele não foi colocado no desenho da instituição como núcleo. Bom, isso tem uma lado que é absolutamente negativo; agora, tem um lado que é positivo, porque - NEAB enquanto núcleo de estudo ele não é necessariamente um grupo de extensão, ou não deveria ser considerado um núcleo de extensão, ele deveria ser considerado um núcleo de estudo. (Entrevista 001 D).

E: o NEAB não é um núcleo que será chamado para fazer essa discussão no conselho universitário, quem serão chamados são os professores [...] que lidam com esse tema. Isso é um problema, porque se nem um de nós [professores] estivermos no Conselho Universitário, você não pauta esse tema, e por outro lado como a administração não tem total consciência da importância do tema e também dependendo da administração ela também não tem vontade política de mexer nesse tema, a gente fica numa espécie de limbo. Você fica na dependência de uma ação política, de um núcleo que não existe na estrutura, ou de professores que estão vinculados a departamentos que nem sempre esse tema é tratado, nem nas disciplinas do departamento. (Entrevista 001 D) (CARDOSO, 2016).

Então, por não compor o organograma da Universidade, o NEAB não tem força política nos Conselhos Universitários (CONSUNI), ainda que seus membros não hesitem em fazê-lo, tal fato tem implicado diretamente nas discussões sobre ações afirmativas e permanência estudantil e de reformulação curricular, entre outros temas importantes para - combate das desigualdades, do racismo e da discriminação nas universidades. Outra dificuldade que atinge os NEABs, e acreditamos não ser um problema específico do NEABUFSCar, é ser responsabilizado como representante da gestão universitária como porta voz das universidades quando são fiscalizadas pelo Ministério da Educação (MEC):

E: [... quando o Ministério Público manda uma requisição pedindo para que a Instituição informe o que está sendo feito, a instituição chama alguém do NEAB e fala "Olha, faça aí um relatório do que vocês estão fazendo". 


\begin{abstract}
[...] Então, você faz um relatório, então aquilo que nós [do NEAB] estamos realizando vira a forma de como a instituição está lidando com o tema, quando na verdade você vai ver o campo normativo em relação ao que está dizendo a LDB? 0 que está dizendo as Diretrizes? Está dizendo outra coisa, está dizendo a temática da cultura afro-brasileira e africana, e a educação das relações étnico-raciais devem atravessar todo o currículo das universidades. Como é que você vai formar professor da educação básica para atender à mudança na LDB se você não mexe na estrutura curricular? (Entrevista 001 D) (CARDOSO, 2016, grifo nosso).
\end{abstract}

0 tripé ensino, pesquisa e extensão, em associação ou na perspectiva da educação das relações étnico-raciais, como expresso no Parecer CNE/CP 3/2004 sobre as Diretrizes Curriculares Nacionais para a formação de Professores da Educação Básica, em nível superior (curso de licenciatura e de graduação plena), pode ratificar o grau de enraizamento e institucionalidade da temática racial. Se analisado nessa perspectiva, podemos afirmar que a proposta de Curso da Pedagogia da UFSCar ainda não leva em consideração os princípios da educação das relações étnico-raciais como orientadores do perfil de identidade docente a ser formado pela instituição, uma vez que o Projeto Político-Pedagógico (PPC) 2012 não menciona explicitamente nenhuma discussão, termos ou conceitos presentes no debate das relações étnico-raciais.

As políticas de ação afirmativa e a expansão do nível superior brasileiro vêm possibilitando trocas e fluxos culturais movimentando as estruturas para se discutir e elaborar política étnico-racial nacional e internacionalmente. Como amostra de que pesquisadores negros têm se preocupado em movimentar a geografia da produção de conhecimento, podemos citar o recente Seminário Afrodescendants in Brazili que reuniu, em abril de 2018, na Universidade de Harvard, em Boston, 30 ativistas e pesquisadores negros brasileiros que movimentaram a geografia para discutir questões referentes ao Brasil.

Na última década alunos negros pobres e indígenas estão se deslocando por todo o País para cursar graduação e pós-graduação fora das cidades e estados de origem. A presença de estudantes indígenas, negros, pobres, pessoas com deficiência, refugiados, população GLBTT, africanos, jovens nordestinos nas universidades do Sul e sulistas nas universidades da região Norte e Nordeste do Brasil são movimentos geográficos que ampliam os diálogos na linha da educação e diferenças. Como as experiências desses estudantes podem contribuir para combater estenótipos e preconceitos regionais? Como a mudança de cidade e estado impactam a construção da subjetividade dos jovens? 
Esse é um fenômeno interessante que merece pesquisa acadêmica para compreender como as diferentes culturas regionais, questões culturais, pessoais, sociais e políticas influenciam os currículos e impactam percepções e mudanças de comportamentos dos sujeitos envolvidos no processo de aprendizagem.

0 Programa de Estudantes-Convênio de Graduação (PEC-G) e o Programa Estudantes-Convênio de Pós-Graduação (PEC-PG) resultado de acordo de cooperação técnico-cultural que o Brasil estabelece desde os anos 1970 com alguns países do continente africano, merece uma análise consistente sobre como essa movimentação geográfica de estudantes pode produzir conhecimento e novos olhares para a África.

Os estudantes dos diferentes países africanos que estudam na UFSCar estão organizados na Comunidade Acadêmica Africana de São Carlos (CAASCAR), conforme definição própria a Comunidade é formada não apenas por estudantes da UFSCar, o grupo é composto por estudantes africanos e alguns brasileiros de outras universidades da Cidade de São Carlos e Região. Durante 10 anos, a CAASCAR realiza a Semana Acadêmica Africana com objetivo de compartilhar a riqueza cultural da África com a sociedade brasileira, em especial a Cidade de São Carlos e região, os estudantes e convidados promovem diversas atividades culturais, palestras e conferências durante a Semana Acadêmica Africana.

É de costume, nessa semana acadêmica, os estudantes da UFSCar promoverem oficinas nas escolas, apresentações de trabalhos acadêmicos, mesas redondas, exibição de filmes, mostras culinárias, exposições fotográficas, entre outras atividades que revelam a diversidade do continente africano. As atividades de cunho mais acadêmico culminam na Festa Africana que reúne estudantes de São Carlos e de outros estados do País, movimentando os fluxos culturais. Na semana acadêmica de 2018 algumas atividades chamam atenção, como, por exemplo, a oficina da língua Crioulo, palestra para professores da rede de ensino, o olhar do mundo sobre a África, lutas e desafios, oficina de língua nacional do Congo.

A presença desses estudantes no Brasil é uma rica fonte de trocas e conhecimentos que vêm auxiliando também no processo de implementação do Ensino da História e Cultura Africana e para fazer cumprir a Lei n. 10.639/03. No entanto, observamos que as universidades têm valorizado pouco as experiências desses sujeitos; isso se deve ao fato de que os laços colonizadores ainda dificultam a compreensão das diferenças como possibilidade de trocas.

Espera-se que a universidade, enquanto espaço intelectual, científico, educativo e político, não continue se mantendo distante e desinteressada das questões que dizem respeito ao diálogo entre culturas e aos direitos dos povos (GONÇALVES e SILVA, 2003). Ainda para a autora, a universidade, ao incluir no quadro de políticas institucionais a reserva de vagas para negros e indígenas, entre outras políticas reparatórias e de reconhecimento, tem que 
passar a admitir que os africanos escravizados trouxeram consigo valores, conhecimentos, tecnologias e práticas que thes permitiram sobreviver e construir a população brasileira. E hoje na condição de estudantes ainda trazem conhecimentos e influenciam o processo formativo "estamos em maio que está acontecendo o mês da África, algumas palestras, tem atividades que são um convênio entre a universidade e o SESC, essa semana mesmo a gente vai ter um debate no palquinho sobre essa questão que se chama até Vim da África o nome do debate." (Entrevistado 013 A) (CARDOSO, 2016).

Segundo a autora, é importante destacar que a universidade no Brasil está sendo convocada a participar da "correção" dos erros históricos, como o colonialismo, a escravidão, o extermínio físico e o simbólico de povos nativos, como os indígenas, com resquícios fortes de preconceito e racismo. Essa é uma responsabilidade da Instituição de modo geral, mas é uma provocação aos NEABs e/ou grupos correlatos no sentido de estabelecer aproximações e projetos consonantes sem que a autonomia dos estudantes seja fragilizada.

A presença dos coletivos nas universidades é um forte termômetro para analisar como as diferenças existentes nelas têm sido agenciadas. Na UFSCar o coletivo Café das Pretas surgiu a partir da necessidade de as mulheres negras, matriculadas em diferentes cursos de graduação e pós-graduação nas áreas de exatas, humanas e biológicas, compartilharem situações racistas e hiperssexualizadas vivenciadas na universidade com objetivo de buscar apoio afetivo e psicológico entre pares, além de propor estratégias de luta.

0 feminismo negro tem garantia de inserção na Universidade em virtude da presença de jovens negras estudantes, ingressantes via ações afirmativas, embora a matriz curricular dos cursos de graduação e pós-graduação não tenha abertura para tais temas.

A pluralização da ciência tem suas possibilidades ampliadas com a presença das diferenças nas universidades. Nesse sentido as ações afirmativas e os desdobramentos dessas políticas nas pesquisas, nas matrizes curriculares do ensino superior e na formação de coletivos de estudantes e intercambistas.

Os intercâmbios acadêmicos também se inserem nesse propósito de construir redes que possibilitem fluxos e trocas capazes de produzir conhecimento e pluralizar ciências. Em nossas perceptivas essa é a atual tarefa das universidades brasileiras contempladas no Edital SECADI/CAPES n. 2, de 29 de maio de 2014, da Secretaria de Educação Continuada, Alfabetização, Diversidade e Inclusão do Ministério da Educação e da Coordenação de Aperfeiçoamento de Pessoal de Nivel Superior.

0 Programa de Desenvolvimento Acadêmico Abdias Nascimento surgiu em resposta às reivindicações do movimento negro à inserção de estudantes oriundos dos programas de ações afirmativas no ensino superior, oferecendo formação e oportunidades de mobilidade 
internacional em cooperação com grupos de estudos e de pesquisas de universidades no exterior.

0 programa objetiva também incrementar o intercâmbio acadêmico entre instituições de pesquisa e ensino superior no Brasil e no exterior, de modo a proporcionar a realização de atividades conjuntas de pesquisa, de desenvolvimento tecnológico e de inovação com parceiros estrangeiros, especialmente na área de tecnologia assistida, bem como atender, preferencialmente, a candidatos autodeclarados pretos, pardos, indígenas e pessoas com necessidades especiais, transtornos globais do desenvolvimento e altas habilidades e superdotação.

Em 16 de novembro de 2015, o NEAB-UFSCar foi contemplado no âmbito do Programa Abdias do Nascimento, com o projeto intitulado Conhecimento, pesquisa e inovações curriculares na formação de professores para a diversidade étnico-racial no ensino superior: questionamentos e contribuições das matrizes étnico-raciais e culturais, de saberes africanos e afrodescendentes.

Em suma, o projeto de pesquisa desenvolvido pelo NEAB-UFSCar visa estabelecer uma rede transnacional de investigação conjunta entre pesquisadores e pesquisadoras de núcleos de estudos sobre a questão racial de universidades brasileiras em parceria com três instituições internacionais: Universidad Distrital Francisco José de Caldas (Colômbia), Georgia State University (EUA) e Université Paris Nanterre (França), núcleos que vêm desenvolvendo pesquisas na formulação e execução de políticas públicas de promoção da equidade racial em seus países.

A intenção a partir do projeto é propor caminhos de descolonização das ciências, retomando visões de mundo, conteúdos e metodologias das quais a ciência ocidental se apropriou, acumulou e utilizando-se deles criou os seus próprios dogmas, deixando de mencionar as origens. São pouco conhecidas e difundidas as bases africanas, árabes, chinesas e dos povos nativos das Américas, a partir das quais foram gerados os fundamentos das ciências e filosofias atuais (SILVÉRIO; SILVA, 2003, p. 49).

Trinta e dois projetos de diferentes universidades brasileiras foram contemplados pelo Edital SECADI/CAPES n. 2, de 29 de maio de 2014, envolvendo professores e alunos da graduação e pós-graduação para executar suas propostas. 0 programa encontra-se em execução, portanto apresenta resultados parciais; no entanto uma questão é urgente de ser pautada, o Programa Abdias Nascimento pela sua origem nas demandas do movimento negro tem um caráter afro-diásporo e convida professores proponentes e estudantes intercambistas a ultrapassarem as barreiras disciplinar e fragmentada que estruturam as universidades desde a Reforma Universitária n. 5.540/68 para produzir conhecimento, pluralizar a ciência e estabelecer trocas capazes de romper com padrões desiguais e discriminatórios. 


\section{CONSIDERAÇÕES FINAIS}

0 processo de implementação de políticas de ação afirmativa no ensino superior tem se tornado um grande desafio para os gestores e a comunidade acadêmica, no sentido de que os conhecimentos produzidos nesse nível de ensino devem contemplar as várias matrizes culturais de seus alunos, eliminando padrões discriminatórios e de desigualdade. Neste artigo tivemos como objetivo apresentar, de forma crítico-propositiva, algumas práticas políticos-pedagógicas a partir de ações do NEAB-UFSCar, utilizando-se da sua experiência enquanto núcleo representativo, no cenário brasileiro, na compreensão das discussões étnico-raciais (políticas de ação afirmativa, a formação de professores, educação para a diferença etc) em face à proposição de um trabalho em parceria com três instituições internacionais, núcleos importantes no estudo das políticas públicas de promoção da equidade racial em seus países.

Estruturamos o texto a partir da breve trajetória do NEAB, explicitando por meio de trechos de entrevistas com alunos a atuação de docentes no ensino, na produção científica e na participação em eventos científicos, acervos bibliográficos, coletivos de estudantes negros, políticas de ação afirmativa formam um conjunto de dados utilizados pelos discentes e docentes entrevistados para construção do discurso sobre a UFSCar enquanto instituição singular no debate das relações raciais no Brasil.

Apresentamos um levantamento sobre a produção bibliográfica na graduação e pós-graduação e constatamos que uma docente membro no NEAB é responsável por 20 pesquisas das 47 produzidas no âmbito do Programa de pós-graduação da UFSCar entre 2005 e 2015. A baixa produção de TCCs sobre relações raciais, entre 2003 e 2008 , é um indicativo da falta de investimento à pesquisa em nível de graduação e demonstra a urgência de os NEABs pautarem a necessidade de mudanças curriculares, a importância dos PIBIC - Ações Afirmativas, programa de extrema importância que se tornou secundário pelas recentes políticas de cortes/restrições orçamentárias.

Apesar da baixa incidência de TCCs, a presença de docentes e componentes curriculares específicos que abordam a temática racial aparece como um fator que instiga alunos a pesquisarem sob o olhar da educação das relações étnico-raciais e diferenças, como podemos constatar com o aumento de quatro para nove pesquisas após o curso passar a oferecer componentes obrigatórios e optativos entre 2010 e 2014. A produção de pesquisa de iniciação científica é de extrema relevância para a qualidade acadêmica, já que é nesse período que os alunos elaboram importantes projetos iniciais que podem ser 
aprofundados em nível de pós-graduação, além disso é nessa experiência que aprendem as metodologias e regras dos trabalhos acadêmicos.

0 NEAB é citado por todos os estudantes entrevistados como fundamental para a aprovação das ações afirmativas, ações do Centro Acadêmico e principalmente na apropriação de conteúdos necessários à formação de professores. A Instituição apresenta potenciais espaços formativos para a formação na perspectiva da ERER, além dos Coletivos, eventos científicos, ACIEPs, componentes ministrados pelo Departamento de Sociologia (DS), - NEAB é indicado pelos alunos como "outros espaços formativos" que foram fundamentais para ampliar conhecimentos sobre educação das relações étnico-raciais.

No entanto, foram identificadas fragilidades para enraizamento das demandas legais para a educação das relações étnico-raciais; uma delas se expressa no fato de o NEAB não fazer parte do organograma e não participar da dotação orçamentária da UFSCar, fatores que excluem sua participação direta nas discussões do CONSUNI, responsável por discutir e decidir o Projeto de Desenvolvimento Institucional (PDI).

As representações sobre a Instituição são postas em questionamento quando se identificam os problemas das políticas de permanência estudantil, como denunciadas por coletivos de estudantes negros. A ausência e/ou a precarização das políticas de permanência estudantil colocam em risco o projeto de universidade democrática, produtora de conhecimento plural com a participação dos diferentes grupos étnicos, raciais, de gênero e faixas de renda.

Se naquele contexto em que foi desenvolvida a pesquisa, 2014 e 2015, a UFSCar foi reconhecida pelos alunos entrevistados como uma das instituições mais democráticas no País, recentemente nos deparamos com cortes orçamentários nas políticas de assistência estudantil que colocam em risco a permanência de alunos negros, indígenas e pobres, esvaindo lutas históricas construídas na linha da educação e diferenças. Essas são demonstrações da difícil tarefa de romper padrões desiguais e discriminatórios e da implementação dessas políticas, que estão em risco quando dissociadas das condições de permanência desses estudantes no ensino superior.

Reunindo os dados das entrevistas quando os participantes da pesquisa se referiam à UFSCar, constatamos que internamente há a produção de um discurso afirmativo que busca inscrever a Universidade como referência qualificada no debate brasileiro sobre ações afirmativas e relações raciais. Constata-se que esse discurso é construído com base na personificação da atuação política e acadêmica de docentes membros do NEAB.

Os dados enfatizam a importância de discentes e docentes negros nas decisões políticas das universidades, o atual cenário político, colonizador, sexista, machista, fascista, marcado por retrocessos sociais, é um alerta da necessidade da luta para a manutenção das 
conquistas, bem como demanda aos pesquisadores, militantes e principalmente egressos das políticas de ação afirmativa a se comprometerem com a produção de conhecimento capaz de romper com desigualdades e discriminações.

Como continuidade das suas ações o Programa Abdias Nascimento e o Projeto desenvolvido pelo NEAB inserem-se nesse desafio de lutar contra retrocessos e perseguem o objetivo de produzir conhecimentos e pluralizar a ciência por meio de pesquisa comparativa e colaborativa com as universidades Parceiras: Universidad Distrital Francisco José de Caldas (Colômbia), Georgia State University (Estados Unidos) e Université Paris Nanterre (França), com intenção de auxiliar a própria UFSCar, dados os resultados apresentados neste artigo, e outras instituições brasileiras a conhecerem práticas pedagógicas, inovações curriculares e matrizes étnico-raciais, culturais de saberes africanos para o processo da formação de professores, principalmente nos Cursos de Pedagogia e Biologia, áreas que são foco de análise no Programa Abadias NEAB-UFSCar.

\section{REFERÊNCIAS}

ASSOCIAÇÃO BRASILEIRA DE PESQUISADORES NEGROS - ABPN. Catálogos ABPN. Disponivel em: https:// www.abpn.org.br/catalogos-abpn. Acesso em: 18 maio 2018.

BRASIL. Conselho Nacional de Educação. Câmara de Educação Básica. Resolução CNE/CP n. 1, de 17 de junho de 2004. Institui Diretrizes Curriculares Nacionais para a Educação das Relações Étnico/Raciais e para o Ensino de História e Cultura Afro-Brasileira e Africana. Brasília, DF, 2004a.

BRASIL. Lei $n$. 7.467, de 20 de dezembro de 1985. Inclui entre as contravenções penais a prática de atos resultantes de preconceito de raça, de cor, de sexo ou de estado civil - nos termos que conhecemos atualmente. Brasilia, DF, 20 dez. 1985.

BRASIL. Parecer CNE/CP n. 003/2004. Diretrizes Curriculares Nacionais para a Educação das Relações Étnico/Raciais e para o Ensino de História e Cultura Afro-Brasileira e Africana. Brasília, DF, 2004b.

CARDOSO, I. A. Educação das relações étnico-raciais: limites e possibilidades no curso de pedagogia da UFSCar. 2016. 222 f. Dissertação (Mestrado em Educação) - Universidade Federal de São Carlos, São Carlos, 2016.

CARDOSO, I. A.; SANTOS, F. V.; RODRIGUES, T. C. Relações étnico-raciais na produção científica do PPGE/ UFSCar. Revista Eletrônica de Educação, v. 11, n. 1, p. 68-85, jan./maio 2017.

CHAUÍ, M. Escritos sobre a universidade. São Paulo: Editora Unesp, 2001.

GOMES, N. L. 0 Movimento Negro Educador: saberes construidos nas lutas por emancipação. Petrópolis: Editora Vozes, 2017. 
GONÇALVES e SILVA, P. B. As relações étnico-raciais precisam ser reeducadas para que de fato todas as pessoas possam exercer plenamente a sua cidadania. Entrevista Informativo outubro/novembro 2012 - FAl-UFSCar. 2012. Disponivel em: http://www.fai.ufscar.br:8080/FAl/noticias/201cas-relacoes-etnico-raciais-precisam-ser-reeducadas-para-que-de-fato-todas-as-pessoas-possam-exercer-plenamente-a-sua-cidadania201c. Acesso em: 20 dez. 2014.

GONÇALVES e SILVA, P. B. Negros da Universidade e produção do conhecimento. In: SILVÉRIO, V.; SILVA, P. B. G. Entre a injustiça simbólica e a injustiça econômica. Brasília, DF: INEP, 2003.

OLIVEIRA, E. R. Narrativas de Thereza Santos - contribuições para a educação das relações étnico-raciais. 2008. Dissertação (Mestrado em Educação) - Universidade Federal de São Carlos, São Carlos, 2008.

PASSOS. J. C. Relações raciais, cultura acadêmica e tensionamentos após ações afirmativas. Educação em Revista, Belo Horizonte: UFMG, v. 31, n. 2, p. 155-182, abr./jun. 2015.

SANTOS, B. S. de. A universidade no século XXI: para uma reforma democrática e emancipatória da Universidade, 2004.

SANTOS, B. Para Além do Pensamento Abissal: Das linhas globais e uma ecologia dos saberes. Novos Estudos, n. 79, nov. 2007.

SANTIAGO, F. Potencialidades Pedagógicas para a Educação das Relações Etnico-raciais em imagens integrantes da Coleção Professor Eduardo de Oliveira e Oliveira. 2010. 66 f. Trabalho de Conclusão de Curso (Graduação em Pedagogia) - Universidade Federal de São Carlos, São Carlos, 2010.

SILVA, C. P. Centro de Cultura Afro-brasileiro Congada de São Carlos. Cad. Pesquisa, v. 63, 1987. Disponível em: http://www.fcc.org.br/pesquisa/publicacoes/cp/arquivos/627.pdf. Acesso em: 20 dez. 2014.

SILVÉRIO, V.; SILVA, P. B. G. Entre a injustiça simbólica e a injustiça econômica. Brasília, DF: INEP, 2003.

TRAPP, R. P. Eduardo de Oliveira e Oliveira sobre a USP: "nós temos direito a essa instituição. 2017. Disponivel em: https://www.geledes.org.br/eduardo-de-oliveira-e-oliveira-sobre-usp-nos-temos" -direito-essa-instituicao/. Acesso em: 5 abr. 2018.

Z'AFRICA BRASIL. Disponivel em: http://www.zafricabrasil.com.br/site/?.page_id=50. Acesso em: 5 abr. 2018.

Endereços para correspondência: DTPP/CECH/UFSCar, Rodovia Washington Luís, Km 235, SP 310, 13565-905, São Carlos, São Paulo, Brasil; tatiane.cosentino@gmail.com 
